\title{
RIO SOLIETTE (HAITI): AN INTERNATIONAL INITIATIVE FOR FLOOD-HAZARD ASSESSMENT AND MITIGATION
}

\author{
S. Gandolfi ${ }^{\text {a }}$, A. Castellarin ${ }^{\text {a }}$, M. Barbarella ${ }^{\text {a }}$, A. Brath ${ }^{\text {a }}$, A. Domeneghetti ${ }^{\text {a }}$, L. Brandimarte ${ }^{\text {b }}$, G. Di Baldassarre ${ }^{\text {b }}$ \\ ${ }^{a}$ DICAM University of Bologna, Bologna, Italy name.surname@unibo.it \\ ${ }^{\mathrm{b}} \mathrm{UNESCO}$, Delft, The Netherlands
}

KEY WORDS: Hazards, Surveying, Developing countries, Hydrology, Cooperation, GPS, Disaster, DEM

\begin{abstract}
:
Natural catastrophic events are one of most critical aspects for health and economy all around the world. However, the impact in a poor region can impact more dramatically than in others countries. Isla Hispaniola (Haiti and the Dominican Republic), one of the poorest regions of the planet, has repeatedly been hit by catastrophic natural disasters that caused incalculable human and economic losses. After the catastrophic flood event occurred in the basin of River Soliette on May 24th, 2004, the General Direction for Development and Cooperation of the Italian Department of Foreign Affairs funded an international cooperation initiative (ICI) coordinated by the University of Bologna, that involved Haitian and Dominican institutions.Main purpose of the ICI was hydrological and hydraulic analysis of the May 2004 flood event aimed at formulating a suitable and affordable flood risk mitigation plan, consisting of structural and non-structural measures. In this contest, a topographic survey was necessary to realize the hydrological model and to improve the knowledge in some areas candidates to be site for mitigation measures.To overcome the difficulties arising from the narrowness of funds, surveyors and limited time available for the survey, only GPS technique have been used, both for framing aspects (using PPP approach), and for geometrical survey of the river by means of river cross-sections and detailed surveys in two areas (RTK technique). This allowed us to reconstruct both the river geometry and the DTM's of two expansion areas (useful for design hydraulic solutions for mitigate flood-hazard risk).
\end{abstract}

\section{INTRODUCTION}

During last decades, Isla Hispaniola, the island shared by Haiti and the Dominican Republic (Figure 1), experienced several natural disasters that causes thousand fatalities and incalculable damages to structures and environment. A recent and striking example is represented by the catastrophic flood occurred in the transnational basin of River Soliette on May 24th, 2004, where a devastating flash-flooding killed over 1000 Haitian and Dominican people, leaving behind desolation and poverty.

Considering the high frequency with which Isla Hispaniola is hit by these kinds of extreme events (i.e. hurricanes) and its economical weakness, the General Direction for Development and Cooperation of the Italian Department of Foreign Affairs funded through the Istituto Italo-Latino Americano (IILA, www.iila.org) an international cooperation initiative (ICI), coordinated and directed by the University of Bologna. The ICI involved Haitian and Dominican institutions and local experts, pursuingtwo main objectives: (a) institutional capacity building on flood risk management and mitigation measures and policies; (b) formulation of a suitable and affordable flood risk mitigation plan. Training and capacity building addressed in particular advanced topographical surveying techniques, which were dealt with both theoretically, through a series of seminars and lectures, and practically, through several field activities.

Considering the importance of accurate 3D models of the earth's surface in various fields of application (Pirotti et al., 2013) this paper summarizes the ensemble of topographical and hydraulic analyses carried out for the evaluation of several flood risk mitigation measures along the River Soliette.

\section{STUDY AREA}

The study area consists of the trans-boundary catchment of River Soliette (Figure1). The drainage area of the catchment is c.a. $135 \mathrm{~km}^{2}$, of which about $80 \%$ (upper basin) belongs to Haiti and $20 \%$ (lower basin) to the Dominican Republic. Streamchannel slopes range from $17 \%$ (upper basin) to $2 \%$ (lower basin).

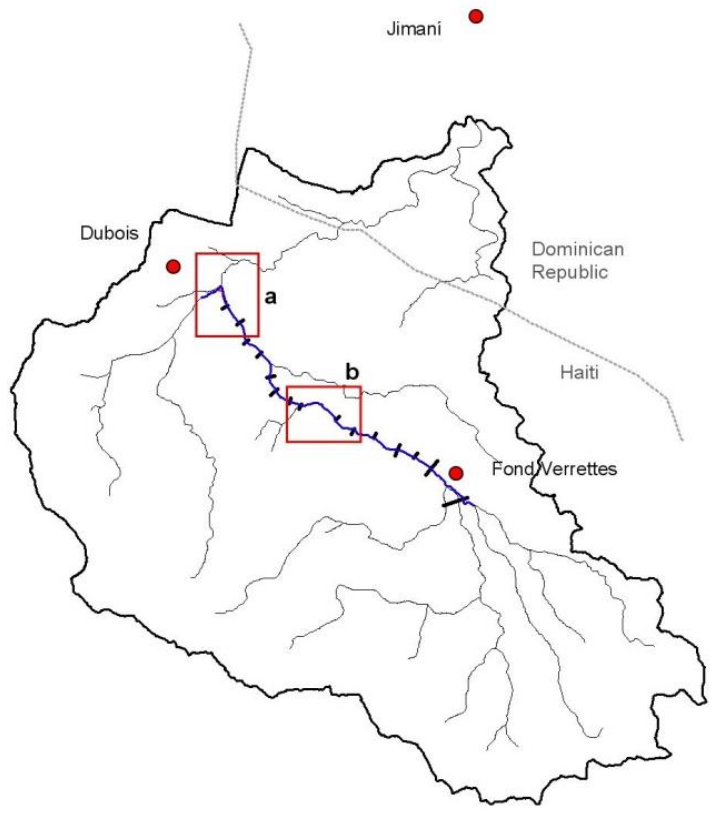

Figure 1. Trans-boundary study catchment of the River Soliette: principal hydrograph network (black tin line), modelled reach (blue tick line) and river cross-sections (black segments); boxes: areas of interest for detailed topographic survey

The stream is ephemeral in nature, with periods of no flow occurring in most years. Only a few direct measurements of discharge have been made, all at low flows (see Smith and Harp, 2004). Because of the extreme poverty conditions of this particular area, most of the Haitian territory is affected by an intense deforestation process along the steep slopes of the river 
basin, being wood the main source of energy for the population. There are two main urbanized areas in the basin: Fond Verrettes in Haiti and Jimaní in the Dominican Republic (Figure 1).

In particular, Fond Verrettes lies on a wide plain area in the Haitian mountain side of the River Soliette, surrounded by steep slopes. Until the 2004 flood event, Fond Verrettes and Jimaní expanded over years, getting in proximity to the main channel (Fond Verrettes), or occupying rather large portions of the alluvial bed of the River Soliette (Jimaní). "When large floods occur, the existing main channel may be abandoned by the river and a new channel may be formed. The process, called channel avulsion, is unpredictable and usually is accompanied by extensive sediment deposition as the flow loses its energy to transport sediment loads on the low-gradient fan area. This process occurred in Jimani during the flood of 24 May" (Smith and Harp, 2004). Evidently, the unplanned and uncontrolled expansion of Fond Verrettes and Jimaní increased significantly the vulnerability of the area to flooding.

The Direction for Development and Cooperation of the Italian Department of Foreign Affairs, through the IstitutoItalo-Latino Americano (IILA, www.iila.org), funded an international cooperation initiative (ICI), coordinated and directed by the University of Bologna, which involved Haitian and Dominican institutions and consisted in two main components: (a) institutional capacity building on flood risk management and mitigation measures and policies; (b) formulation of a suitable and affordable flood risk mitigation plan consisting in structural and non-structural measures. The main outcomes of the ICI for the upper Soliette catchment (i.e. Haitian portion) are briefly presented in Section 5.2.

Brandimarte et al. (2009), in the context of this ICI, provided a first comprehensive hydrological analysis of the considered historical flood event, highlighting that the May 2004 event was characterized by an exceptional intensity and by an intensive sediment transport. In particular, intense soil, fluvial erosion and impulsive sediment transport (in some cases boulder of about 2-3 m) were responsible for most of the damages occurred during the event. Especially in the upper and central part of the catchment (Figure 1), due to steep slopes (around 17\% on the upper basin) and deforestation process that increase soil erodibility (Pirotti et al., 2012), flash-floods can move large volumes of sediments and represent a big risk for urban areas situated along the reach or in the lower part of the catchment (i.e. Jimaní). In the light of these considerations, Brandimarte et al. (2009) proposed a rather complex compound of structural (i.e.check dams, embankments) and non-structural measures (i.e. early-warning system) that should be implemented at catchment scale for the mitigation of the flood-risk.

Focussing in particular on the lower portion of the catchment where hydrological and topographical information were more extensive and accurate, they identified a set of measures for the protection of the urban area of Jimani: masonry lengthwise embankments for flood restraint in proximity of urban areas (structural measure), and mainly, a series of non-structural measures, such as the delineation of flood prone areas for controlling urban expansion, environmental education campaign for people leaving on floodable area and the implementation of a flood warning system. These latter measures, usually identify as "non-structural" interventions, pursued flood risk mitigation addressing the vulnerability of people and the adaptive capacity of the society (e.g. emergency plan, risk communication and risk education). Therefore, considering that they usually require lower economical efforts if compared with alternative structural measures, their implementation appears the most suitable strategy for the persuading of flood risk mitigation in the study area.
Starting from these outcomes, the present work took advantage of more extensive topographical surveys carried out on the upper part of the catchment, that were not available during previous studies, in order to further investigate flood mitigation measures along the River Soliette.

\section{TECHNICAL REQUIREMENTS FOR HYDRAULIC MODELLING, OPERATIVES CONSTRAIN AND LOGISTICAL ASPECTS.}

A digital topographic model of the Soliette river bed was needed to perform the numerical hydrodynamic simulations of the flood event required by the planning and design the flood hazard mitigation measures.

In particular, given the single-channel nature of the upper portion of the Soliette stream, a one-dimensional hydrodynamic model can perform an accurate mathematical representation of the hydraulic behaviour of the stream provided a suitable representation of the riverbed geometry through a series of traditional cross-sections (see Figures 1 and 2). High resolution DEMs were instead needed for two separate areas where preliminary surveys identified suitable locations for the construction of check dams (seeboxes in Figure 1).

Considering the topographic survey of river cross-sections, the constrains for a correct hydraulic simulation (see e.g. Castellarin et al., 2009) were stated as: (i) maximum relative distance between two consecutive sections of about $400 \mathrm{~m}$, and (ii) section length have to be fixed considering that the profile at the boundary heights have to be up to 5-7 meters respect to the river thalweg (Figure 2). The overall length of the surveyed river was about 6-7 km, resulting on the whole on 15 cross-sections (Figure 1).
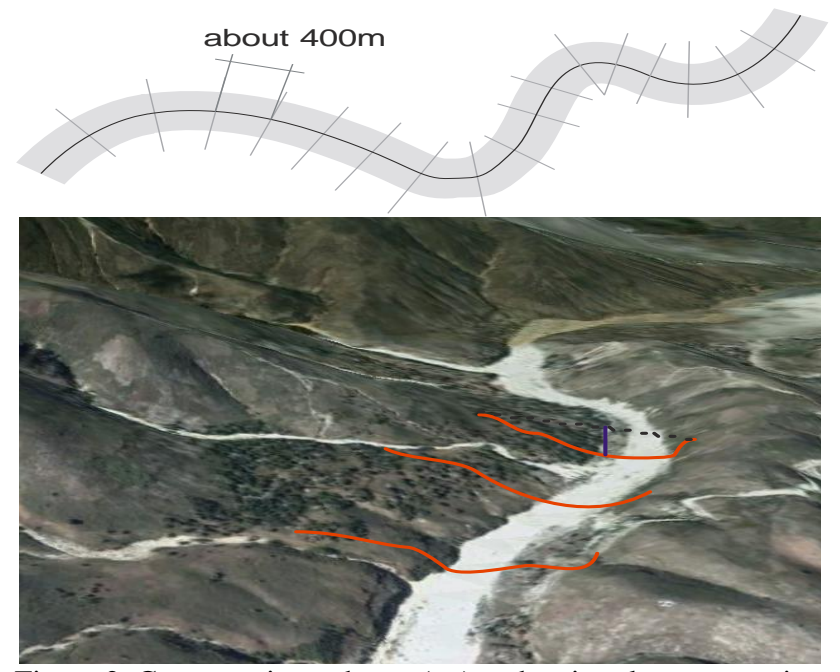

Figure 2. Cross-sectionsscheme (up) and a virtual representation of cross-sections cutlines over the DEM of the River Soliette

Considering the two high-resolution DEMs, the constrains were set considering a river reach corresponding to difference of thalweg altitude between the upstream and downstream sections of about $10 \mathrm{~m}$ (i.e length of the reach $\sim 200 \mathrm{~m}$ ), while the area width was identified by surveying lateral slopes up to $10 \mathrm{~m}$ above the bottom of the riverbed (see Figure 3).

Last limiting boundary condition was the absence, close to the area of interest, of any kind of geodetic infrastructure, mobile phone connections and any connection to the Geodetic National Network (Haitian or Dominican), which resulted in extra-time requirements for survey and also for data processing. 


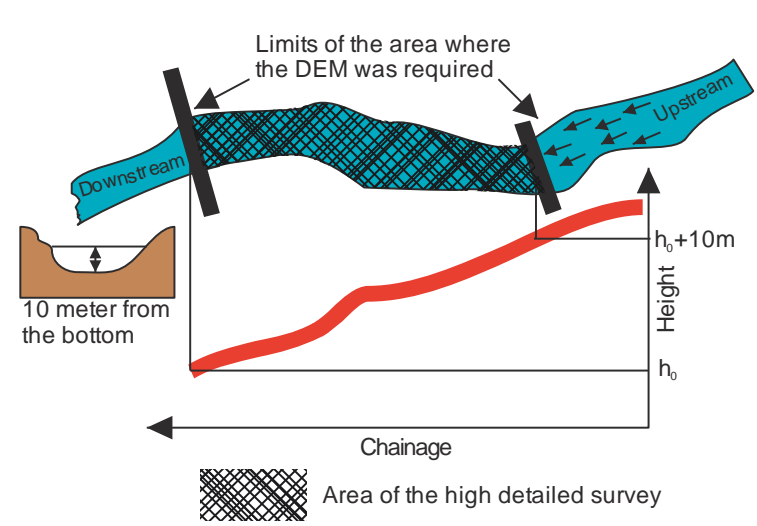

Figure 3. Definition of the boundary limits for the two areas where high detailed survey was required, the longitudinal profile of the riverbed is indicated in red

Considering all these constrains and requirements, we applied particular instrumentation, planning and surveying methods, which are explainedin detail in the section below.

\section{TOPOGRAPHIC SURVEY}

\subsection{Design and data processing strategy}

Unfortunately the site location combined with the short time available (less than one week) and the restricted founds for this operation have not permitted the employment of new and sophisticates instrumentation such as Airborne or Terrestrial Laser Scanner that have to be considered as the optimal solution for this kind of work. Starting from all the above limits and constrains the best choice for this kind of survey was the GNSS(Global Navigation Satellites Systems) technique. GNSS receivers allow both the framing of the survey in an absolute geodetic and cartographic System and the detailed survey of sections and of digital elevation model (DEM) in selected areas. In this way no other topographic instruments are necessary. Concerning the linking of the survey in an absolute system, no vertices of a local geodetic frame were available in the area, but it is possible to obtain the receiver position in an InternationalGeodetic System like ITRS by means of the Precise Point Positioning (PPP) approach for high accurate positioning a posteriori of some temporary points along the valley. PPP is a growing technique that permit high accurate absolute positioning using carrier phase observations acquired by geodetic GNSS receivers (Zumberge et al, 1994). This technique until few years ago was not so consideredfor high accuracy positioning mainly for the reason that the final accuracy was significantly worse than others approach based on double difference carrier phase data processing (HofmannWellenhof et al, 2001). On the other hand, double difference solution require the common acquisition of GNSS observations from more receivers and the final solution can be considered as a relative solution. During the last years the technological advances regarding satellite ephemeris precision, geophysical models, clock models, etc.., has permitted a significant improvement of the PPP and now the overall accuracy is (at least for 24hours windows time observation) comparable to the phase differenced solutions. Some other studies have also demonstrate that the final accuracy is strictly dependent on the windows time observation.

In Figure 4 the experimental accuracy vs the windows time observation is reported by Gandolfi (2009), considering a wide dataset. From figure 4 is possible to see as after few hours of stand-alone observation ( $>3$ hours) the planimetric accuracy can be considered lower than $3 \mathrm{~cm}$ and for the height lower than 10 cm ( $99 \%$ confidence level).

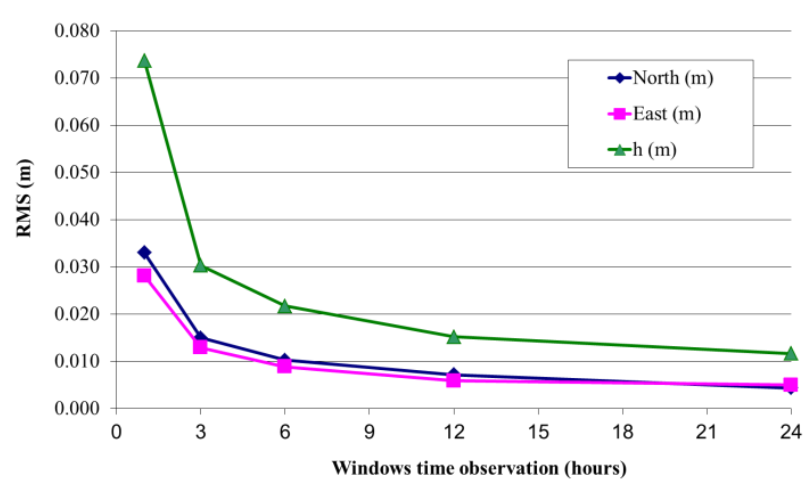

Figure 4. Root Mean Square (RMS) accuracy of GNSS Precise Point Positioning solution vs windows time observation (RMS)

Concerning the Reference Frame, the final position in PPP is typically given in the same geodetic reference frame of the satellites orbits (IGS) and the transformation to the International Terrestrial Reference Frame (ITRF) should be possible applying a daily seven-parameter transformation that, using JPL data products (orbits and clocks) is part of these products. The parameters of this transformation have been evaluated on a worldwide network (FLINN network) where, for each station, official coordinate in ITRF are well known. At the moment many software packages are able to process data in PPP mode but one of the most performing is the GIPSY-OASIS II (developed and maintained by JPL-NASA). This software package has been used in this contest for PPP solution.

For all the above reported reason PPP especially in remote area constitute the best approach for high accurate positioning. Moving to the detailed survey, necessary both for section estimation and DEM realization, Real Time Kinematic (RTK) technique has been adopted.

RTK permit to estimate static or kinematic position of a receiver (Rover) at centimetre level accuracy in real time with respect a fixed reference station (Master), and set the coordinates of the master, even those of the rover are known (Hofmann-Wellenhof e al,2001, Rizos2002). In our application the PPP survey provides precise coordinates in absolute ITRF2000 frame for the Master and therefore also the Rovers positions are straight obtained in the same reference frame.

In this contestRTKsurvey can be useful also for at least a couple of reasons. First of all, the surveyor can check positions, at centimeter level accuracy respect the coordinates of the reference station, in real time on screen of the receiver and then navigate considering the requirement of the survey for the purposes, in this case, of hydrological modelling.Secondly, the connection with the master station permit a continuously data quality check that guarantee the final quality of the positioning also if a post processing is required. Usually the connection between master and roverreceivers can be performed using or mobile or radio link. For this survey VHF radio connection was mandatory because in the area of the survey no mobile phone connection were available. In other hand VHF connection permit the possibility to send RTK corrections to many rover receivers simultaneously and this aspect reduce significantly the timeforsurvey.

From the point of view ofprecision of RTK, many experimentation have been performed (Pirti et al., 2009; Janssen et al., 2011,Garrido et al., 2011). Numerous experiments have 
been performed also by the authors in order to test the accuracy and especially the degree of reliability, since the RTK technique does not allow redundant measures and therefore a intrinsic control of quality. We have performed three surveys at a distance of time and compared the absolute coordinates with each other to test the repeatability of the survey RTK. The average of the three values obtained in real time was then compared with the coordinates obtained from a static GNSSsurvey and from the least squares adjustment of the measured GNSSbaselines, and therefore with very accurate values.

Generally the difference between the mean of RTK surveys and the static solution is very low for planimetric components (less than $1 \%$ differences results greater than $20 \mathrm{~cm}$ ), while the heights are somewhat more scattered and less precise, anyway only $3 \%$ of the height differences exceeds $20 \mathrm{~cm}$ (Barbarella et al. 2006; see Figure 5).

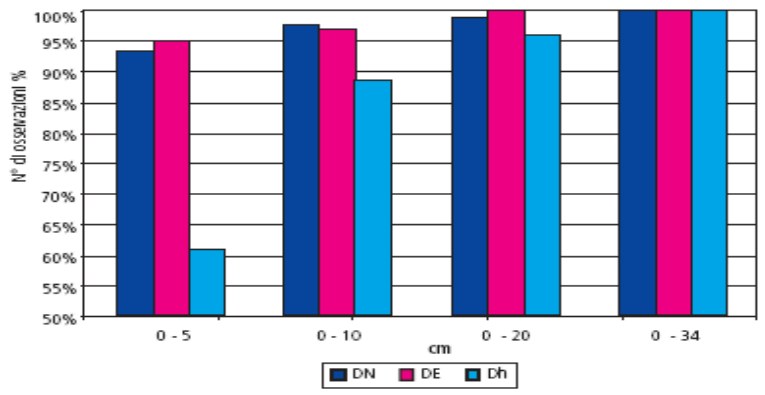

Figure 5. Distribution of the differences between static and real time survey

The precision and reliability of the RTK technique is therefore more than adequate for the type of survey that must be performed.

To minimize the duration of the survey, GNSShas been provided for the use of three GNSS-RTK receivers (two rovers and a master) and in particular the master station was also equipped with a power supply based on flexible photovoltaic panels and electric batteries that guarantee a daily power autonomy.

\subsection{Topographic survey technique, and data processing.}

The accurate phase of logistical planning involving technology, technical mode of technology utilisation and data processing performed in Italy has been fundamental. However not all the aspects could be planned and some decisions have been assumed on site.

Despite the dimension of area permits to consider just one station as master station for RTK (typically RTK correction permit high accuracy within $15 \mathrm{kms}$ ), some others logistical constrains impose the employment of two different master stations along the valley and located close to the surveyed area. The first one was located close to the village where the logistic base was located and continuously supervised from thieves or vandals. This Base station was use for the survey of all the upper part of the Rio Soliette (Figure 6). The second one was successively located close to the bottom part of the area to be surveyed and in correspondence of one of the two areas where the high detailed survey had to be performed (Figure 6).

For the RTK survey fixed coordinates for the two master stations has been obtained by a mean of 20 minutes observation of code single point positioning. The expected absolute accuracy of the obtained coordinates was at meter level. In figure 5the map of the areas and the detailed schemeof the survey is reported including the two reference stations, the two area were high detailed survey had to be performed and the section locations.

During the field operation each GNSS receiver was set up both for a RT positioning and raw data (carrier phase and code) recording with 1 second sampling time. The possibility to record the raw data could be considered very important in these conditions both for a data reprocessing of the master stations in PPP and for a complete reprocessing of the kinematic survey with the new accurate position of the two master stations obtained in PPP.

The involvement of Haitian and Dominican Institutions both for logistical support and training has been very useful also because HINDRY (Dominican) has made available a couple of dual frequency GNSSreceiver (not equipped for RTK but useful for a densification of the survey on the two area where high detailed survey was requested). The acquired data have been processed a posteriori within the others GNSS receiver. The overall number of GNSS receiver used for this survey was 5 and all the work has been possible in 3 working days.

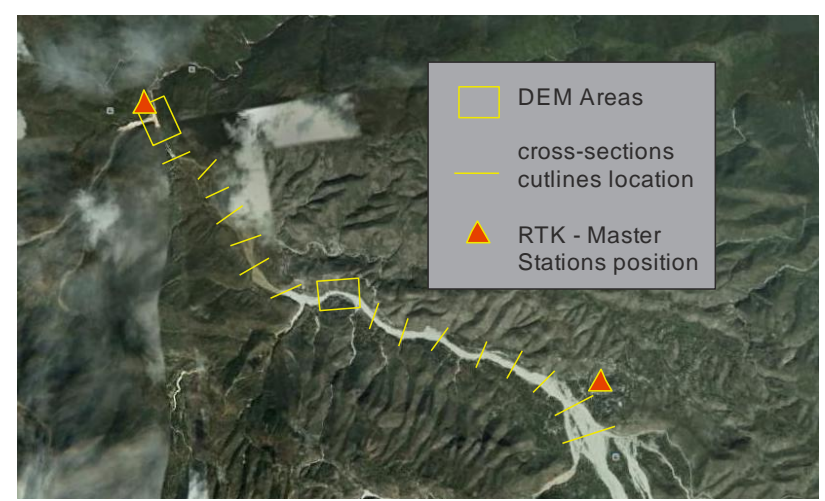

Figure 6. Scheme representing river cross-sections cutlines, the two areas where a high-resolution DEM was needed and the position of the two GNSS Master stations

After the data processing phase (that for kinematic survey was performed with Trimble Geomatic Office), all section and the two high detailed survey have been available in the same reference frame (ITRF2000) but in geodetic Coordinates.
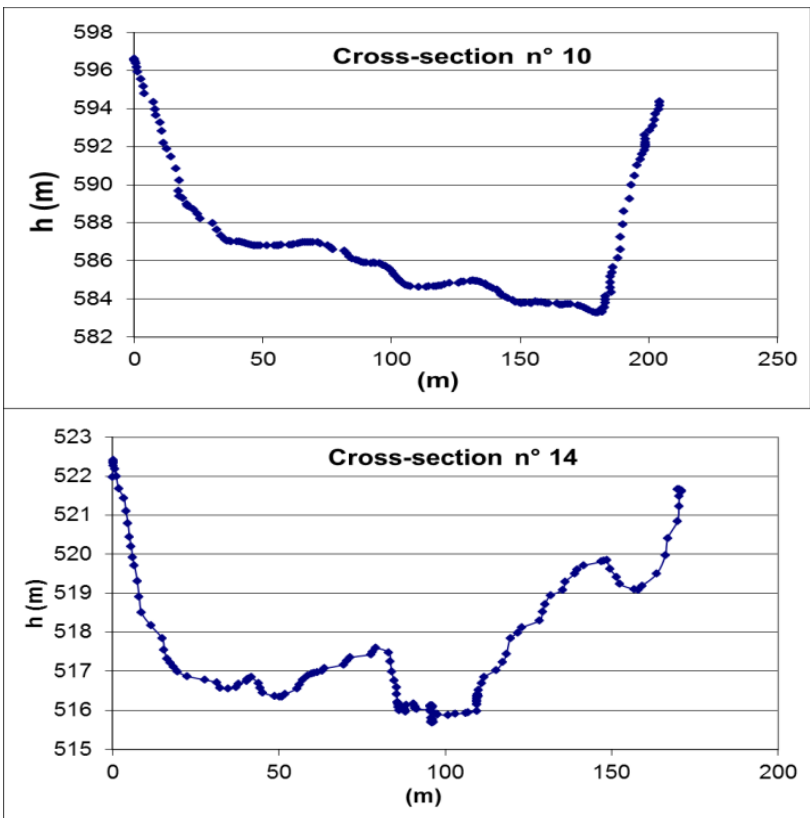

Figure 7. Two examples of river cross- sections surveyed by GNSSalong the upper part of the River Soliette 


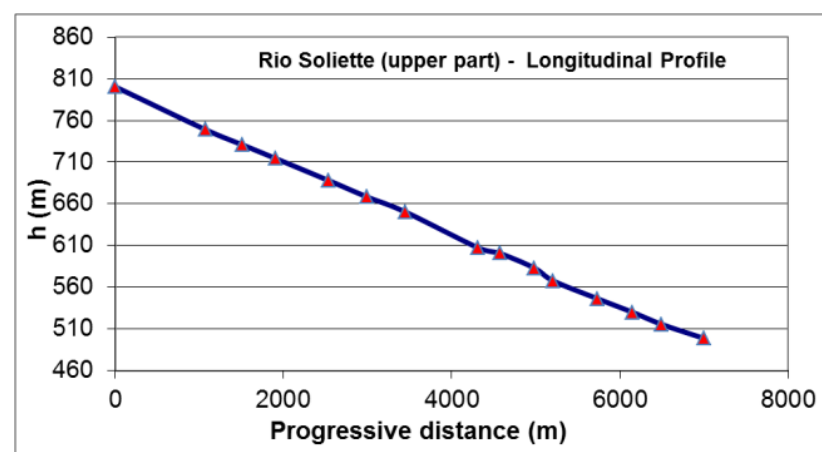

Figure 8. Longitudinal profile of the upper part of the River Soliette

In order to manage these data into the hydraulic model these coordinates have been transformed in a cartographic projection (UTM, zone 18). The heights have been transformed from ellipsoidal to orthometric ones by using EGM96 geoid model and assuming the geoidal undulation as a constant for all the area. Considering the two areas were high detailed survey have been performed, starting from the surveyed profile a DEM (1 meter resolution) as been realized using kriging geostatistical interpolator. In Figure 7,8,9examples of cross and longitudinal sections and an example of DEM have been reported.

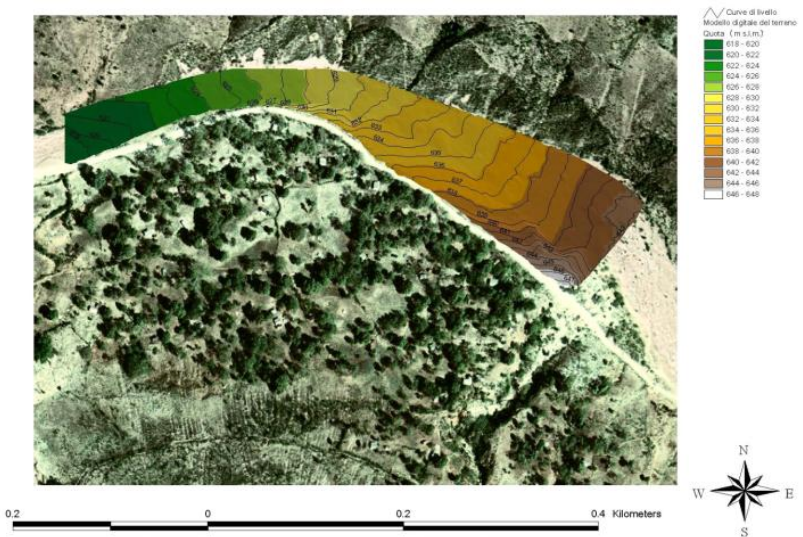

Figure 9. Example of a DEM derived from the GNSS high detailed survey

\section{UPPER SOLIETTE BASIN: HYDRAULIC ANALYSES AND HYPOTHESISED FLOOD-RISK MITIGATION MEASURES}

\subsection{Hydraulic Analyses}

Brandimarte et al. (2009), within the same ICI, simulated the May 2004 flood event by means of a quasi-distributed hydrological model that was implemented for the comprehensive trans-boundary basin. In particular, referring to topographic and morphological information provided by local authorities (e.g. land-use, soil-type variability and a coarse DEM for the whole river basin) the catchment was divided into several sub-basins for the implementation of the rainfall-runoff hydrological model (for more details on the reconstruction of the May 2004 flood event refer to Brandimarte et al., 2009).

Given the absence of a reliable data series relative to historical flood occurred over the study area and considered the extreme intensity of the May 2004 event, we referred to it for the evaluation of flood risk mitigation strategies along the River Soliette.

Table 1 reports the estimated discharge values used as hydraulic boundary conditions for the numerical analysis (see Figure 1).

\begin{tabular}{|l|c|}
\hline River Station & Peak discharge $\left[\mathrm{m}^{3} / \mathrm{s}\right]$ \\
\hline Fond Verrettes & 1340 \\
\hline Ravin Dubois & 1881 \\
\hline
\end{tabular}

Table 1. Peak discharge values estimated for the 2004 flood event (Brandimarte et al., 2009)

With the aim to deepen flood risk mitigation strategies for the upper part of the catchment we referred to the collected set of topographical information for the implementation of a monodimensional hydraulic model (1-D model) of the upper reach of River Soliette. Figure 1and 6 show the position of 15 crosssections surveyed along the river, specifically along the stretch that goes from the urban area of Fond Verrettes to the confluence of River Ravine Dubois (left tributary relative to Dubois sub-basin). The 1-D model was built referring to the UNET code (Barkau, 1997) that numerically solves the SaintVenant equations, through an algorithm that uses a classical implicit four-point finite difference scheme (Preissmann, 1961). Once implemented and calibrated, the 1-D hydraulic model represents a useful tool for the investigation of several fluvial geometric configurations, testing the efficiency and validity of different hydraulic structures in terms of flood risk mitigation (see e.g. Castellarin et al., 2011; Brath et al., 2010; Pappenberger et al., 2005, for some example on the use of monodimensional model).

Surveyed river-cross sections were used to reproduce the geometrical characteristic of about $7 \mathrm{~km}$ reach of the River Soliette. Furthermore, boxes on Figure 1 and 6 highlight the areas identified as suitable sites for the construction of hydraulic structures finalized to reduce solid transport and for which two detailed DEM were retrieved (1 meter resolution; see Figure 9). For the areas of interest, the geometrical reproduction of the river was improved by means of several additional river crosssections extracted from available DEMs by means of Geographic Information System tools (GIS; see traces on Figures 10 and 11).

Concerning hydraulic parameters adopted on the numerical model, due to the lack of observed hydrometric data, roughness coefficients were defined referring to typical values reported in the literature for river beds of similar characteristics (i.e. coarse sediments, pebbles and big boulders; Chow, 1959).

\subsection{Flood-risk mitigation measures for the upper Soliette basin}

A comprehensive flood risk mitigation plan is usually composed of a series of measures implemented at the catchment scale that ensure a limitation of flood hazard and flood exposure. Brandimarte et al. (2009), considering the upper Soliette basin, suggested the implementation of several nonstructural measures, among which the most important are: strengthening of the pluvio-hydrometric gauging network (actually almost absent), environmental education campaign for the population living in the flood prone areas, the delineation of flood prone areas for controlling urban expansion and the promotion of a reforestation program. In particular, the latter measure sound particularly important in the light of significant problems related to sediment transport observed during May 2004 event on the study area.

As a matter of fact, the most significant efforts planned in terms of hydraulic infrastructures (structural measures) should be 
dedicated to sediment retain, ensuring the reduction of solid deposition in the lower part of the catchment (i.e. alluvial fan near Jimaní, Dominican Republic) and avoiding the risk of flow levels rising that could originate floods on the urban area (i.e. alluvial fan near Jimaní, Dominican Republic). Starting from these considerations, the present work investigated the suitability of structural measures to sediment retain in the upper-central River Soliette: a system of three "filtering" dams (also called "selective" or "slit" check dams) was considered as the best solution for retaining solid material; boxes on Figure 1 and 6 show the areas individuated as potential locations. Figure 10 and 11 report a zoom of two identified areas (boxes $a$ and $b$ on Figure 1, respectively) reporting the traces of projected filter dams (grey area), additional river cross-sections extracted from detailed DEMs surveyed during 2008 field trips (yellow traces on Figure 10 an 11), while Figure 12 reports the typical configuration of a slit check dam.

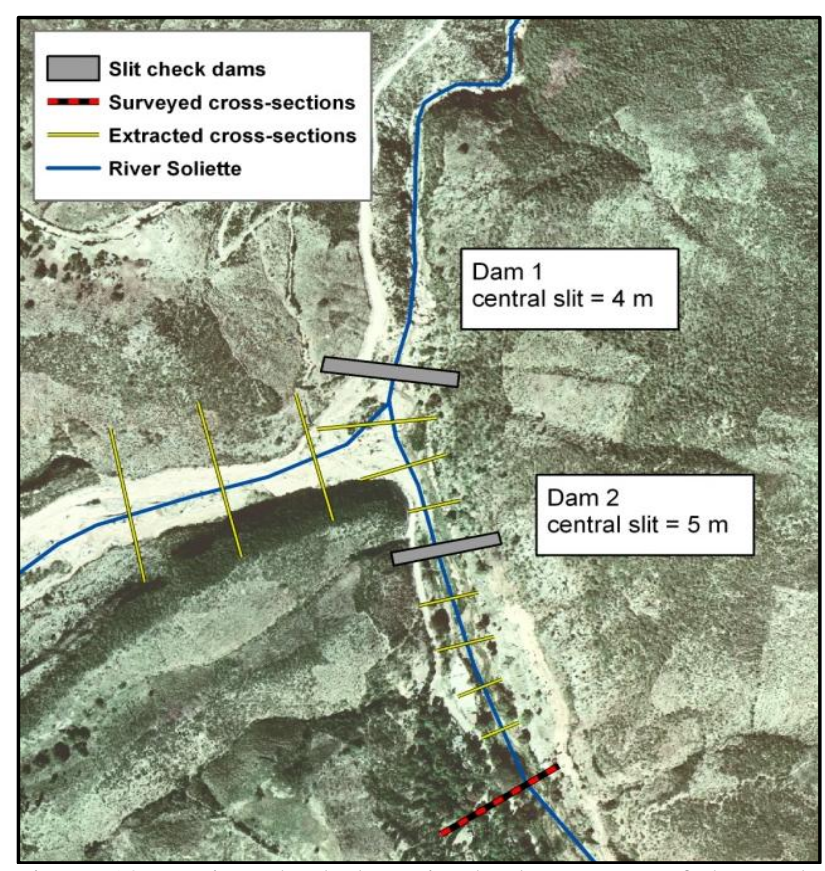

Figure 10. Design check-dams in the lower part of the study area (box ain Figure 1)

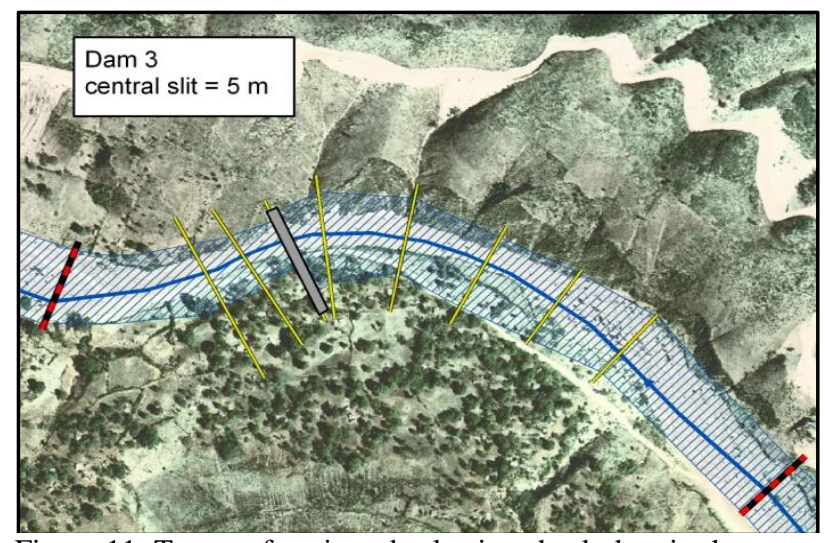

Figure 11. Traces of projected selective check dam in the upper part of the study area (box b on Figure 1) and floodable area for May 2004 event (dashed area)

This kind of dam is usually characterized by one or more narrow, vertical openings, going from the dam base up to the weir. The sediment retain is obtained by means of a backwater effect that allows most of the particles to deposit upstream the dam (hydrodynamic sorting), resulting on structures whose behavior is customized to individual rivers and streams and their specific modalities of sediment transport.

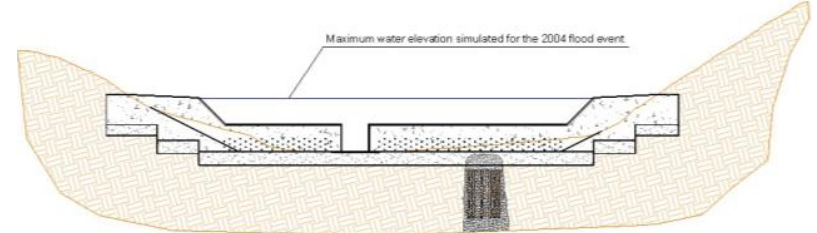

Figure 12 - Selective check dam structure: frontal view of Dam 2 (see also Figure 10) characterized by the vertical opening of about $5 \mathrm{~m}$ width

Final dimensions of projected dams and their interaction on flood propagation dynamics were investigated by means of the implemented 1-D model. As a example, dashed area on Figure 11 highlights the backwater effect due to the filtering dam simulated for the reference event (i.e. May 2004 event), while Figure 13 reports a three-dimensional view of water elevation simulated in correspondence of the third dam (Figure 11).

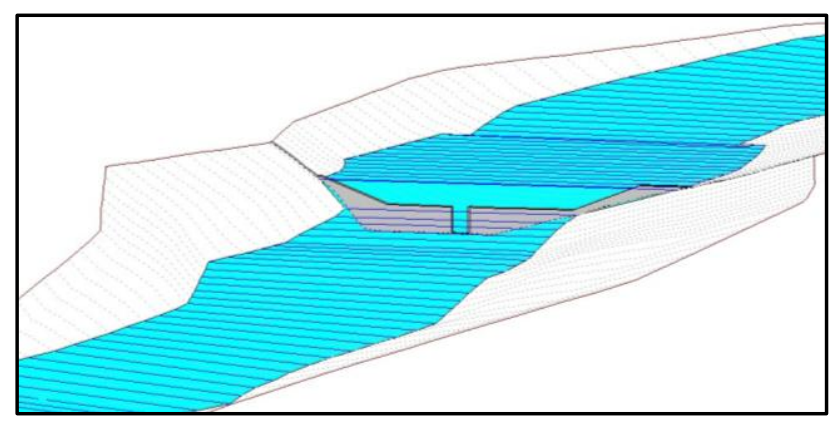

Figure 13. Three-dimensional view of River Soliette near the third slit check dam

\section{CONCLUSIONS}

The present paper summarizes the results obtained within the international cooperation initiative (ICI) coordinated by the University of Bologna that was aimed at preparing a flood-risk mitigation plan in the Isla Hispaniola (Haiti and Dominican Republic). Objectives of the ICI were twofold: a) institutional capacity building on flood risk mitigation for local experts; $b$ ) hydrological and hydraulic analysis of the transnational River Soliette finalized to flood-risk mitigation. The present paper summarizes the topographical techniques and data analysis processes implemented for the geometrical surveys of the upper-central stream of River Soliette (Haiti). River crosssections and two detailed DEMs surveyed and constructed during field trips were usedfor the implementation of a onedimensional (1D) hydraulic model for a $\sim 7-\mathrm{km}$ reach of the river. Referring to the May 2004 flood event occurred on the study area and reproduced by Brandimarte et al. (2009), the 1-D model was used for the formulation of a suitable trans-boundary flood risk mitigation plan, integrating structural and nonstructural measures.

Concerning the design of structural measures, the numerical computations mainly focus on the efficiency of a system of three filtering damsadopted as measures for controlling the impulsive sediment-transport phenomena that occur during large flood events and are among the main issues affecting the upper and central part of the catchment.

As a general remark, the analysis highlighted how aflood risk mitigation planshould be considered as a rather complex compound ofstructural and non-structural measures due to the 
hydrological and morphological heterogeneous characteristics of the study area.

In particular, the study highlights the importance of an appropriate land-use planning and development as a fundamental step for flood-risk mitigation in this area, whose importance is enhanced by extreme poverty conditions of the study area, which severely hamper the possibility construct costly structural flood-mitigation measure. Also, in the context of developing countries (and even more so for trans-boundary basins, as for this case), the generalized lack of hydrological and topographical datamakes the design and implementation of reliable structural measures for flood-risk mitigationsdifficult. Absence of hydrological data prevent from a reliable estimation of expected flood event, while the absence of appropriate topographical data results on unreliable hydraulic analysis.

In these contexts, the opportunity to implement fast and reliable survey techniques such as those presented above appears of utmost importance, especially in the cases where global topographical datasets (i.e. Shuttle Radar Topography MissionDEM; DEM-STRM) do not ensure the resolution and accuracy required for reliable hydraulic investigations.

\section{REFERENCES}

Barbarella, M., Gandolfi, S., Ronci, E., 2006. The Use of a GNSS Test Network for Real Time Application in Italy: First Results Based on Regional Field Test, ION GNSS 19th International Technical Meeting of the Satellite Division, 26-29 September 2006, Fort Worth, TX, USA, 1226-1232.

Barkau, R. L., 1997.UNET One dimensional Unsteady Flow through a full network of open channels, US Army Corps of Engineerings, Hydrologic Engineering Center, Davis.

Brandimarte, L., Brath, A., Castellarin, A., Di Baldassarre, G., 2009. Isla Hispaniola: a trans-boundary flood risk mitigation plan. Physics and Chemistry of the Earth, Special Issue on Integrated water resources assessment, with special focus on developing countries, 34, pp. 209-218.

Brath, A., Castellarin,A., Di Baldassarre, G., Domeneghetti, A., 2010. Linee strategiche di intervento per la mitigazione del rischio alluvionale lungo il corso medio-inferiore del Fiume Po. L'Acqua, 2, pp. 9-24.

Castellarin, A., Di Baldassarre, G., Bates, P.D., Brath, A., 2009. Optimal cross-section spacing in Preissmann scheme 1D hydrodynamic models, Journal of Hydraulic Engineering, ASCE, 135(2), pp. 96-105.

Castellarin, A., Domeneghetti, A., Brath, A., 2011. Identifying robust large-scale flood risk mitigation strategies: a quasi-2D hydraulic model as a tool for the Po River. Physics and Chemistry of the Earth, Volume 36, Issues 7-8, pp. 299-308.

Chow, V. T.: Open-Channel Hydraulics, New York, USA, 1959.

Gandolfi, S., 2009, L'approccio non differenziato (Precise Point Positioning) nel calcolo di posizioni mediante sistemi GNSS, Bollettino SIFET (ISSN 1721-971X), 2009, 1, 121-137.

Garrido, M. S., Gime'nez, E.,Lacy, M. C., Gil, A. J. , 2011.Testing precise positioning using RTK and NRTK corrections provided by MAC and VRS approaches in SE

Spain. Journal of Spatial Science, Vol. 56, No. 2(2011), 169184.
Hofmann-Wellenhof,A., Lichtenegger, H.E Collins J.. GNSS: Theory and Practice (Fifth Revised Edition), New York, Springer-Verlag Wien, 2001.

Janssen, V, Grinter T., Robert, C., 2011. Can RTK GNSS be used to improve Cadastral Infrastructure? Engineering Journal, Volume 15 Issue1x Issn 0125-8281 Jan. 201143.

Kouba, J., Heroux, P., 2000. GNSS Precise Point Positioning using IGS Orbit Products, GNSS Solutions, 5 (2), 12-28.

Pappenberger, F., Beven, K., Horritt, M., and Blazkova, S., 2005. Uncertainty in the calibration of effective roughnessparameters in HEC-RAS using inundation and downstream level observations, Journal of Hydrology, 302,4669, doi:10.1016/j.jhydrol.2004.06.036, 2005.

Pirotti, F., Grigolato, S., Lingua, E., Sitzia, T, Tarolli, P., 2012. Laser scanner applications in forest and environmental sciences. Italian Journal of Remote Sensing, 44 (1), pp. 109-123.

Pirotti, F., Guarnieri, A., Vettore, A. 2013. State of the art of ground and aerial laser scanning technologies for highresolution topography of the earth surface. European Journal of Remote Sensing, 46, pp. 66-78.

Preissmann, A., 1961. Propagation of translatory waves in channels and rivers, Proc., First Congress of French Association for Computation (AFCAL), pp. 433-442.

Pirti, A., Arslan, N., Deveci, B., Aydin, O., Erkaya, H., Hosbas, R.G. , 2009. Real-Time Kinematic GNSSfor Cadastral Surveying Survey Review, 41, 314 pp. 339 - 351 (October 2009).

Rizos, C. , 2002. Network RTK research and implementation A geodetic perspective Journal of Global Positioning Systems 1(2) (2002). 144-150.

Smith, M.A., Harp, E.L., 2004. Flash flooding, debris flows, and hyperconcentrated water flows triggered by high-intensity rainfall of 23-24 May 2004 in southwestern Dominican Republic and south eastern Haiti, Site Assessment, July 16, US Geological Survey.

Zumberge, J.F., Helfin, M.B., Jefferson, D.C., Watkins, M.M., Webb, F.H., 1997. Precise point positioning for efficient and robust analysis of GNSS data from large networks. Journal of Geophysical Research, 102, 5005-5017. 